\title{
Hacia la recuperación de la Historia en Bibliotecología y Documentación
}

\author{
Héctor Guillermo ALFARO LÓPEZ \\ galfaro@cuib.unam.mx \\ Centro Universitario de Investigaciones Bibliotecológicas CUIB. UNAM México
}

Recibido: 02/04/2011

Aceptado: 06/05/2011

\begin{abstract}
RESUMEN
Se hace una reflexión sobre la necesidad de recuperar el conocimiento histórico para fundamentar mejor la Bibliotecología y Documentación (ByD). Se parte del supuesto de que la investigación histórica en ByD gradualmente ha sido dejada de lado debido a que se ha incrementado la investigación referente a temas coyunturales de carácter tecnológico. Para recuperar la dimensión histórica en ByD se analiza la correlación entre la historia y los documentos dentro del contexto bibliotecario. Con lo que se pone de manifiesto que los documentos son producto del desenvolvimiento histórico y que por lo tanto este reconocimiento de la historicidad en ellos contenida contribuye a valorizar desde el ángulo histórico el contenido de los documentos. Todo esto debe de ser motivo para que se recupere a la vez el fundamento humanista de la ByD.
\end{abstract}

Palabras clave: Historia, Bibliotecología, Documentación, Tecnología, Humanismo.

\section{Towards the recovery of the History of Library and Documentation}

\begin{abstract}
It reflects on the need to recover the historical knowledge to help support the Library and Information Science (LIS). It is assumed that historical research in LIS has been gradually sidelined because research has increased regarding current issues of a technological nature. To restore the historical dimension in LIS analyzed the correlation between history and the documents within the library context. Thus shows that the documents are the product of historical development and therefore this recognition of the historicity contained therein contributes to value from the historical angle the content of documents. All this must be a reason to recover both the human basis of the LIS.
\end{abstract}

Key words: History, Librarian Science, Documentation, Technology, Humanism.

\section{INTRODUCCIÓN}

Bibliotecología y Documentación (ByD) en conjunto conforman una ciencia cuyo objeto de estudio, la información registrada, se encuentra en el centro de los procesos sociales y culturales que marcan con su impronta al mundo contemporáneo. Las denominadas sociedades de la información y del conocimiento tienen como fundamento el amplio espectro de fenómenos y procesos referentes a la información, la cual se ha convertido en una mercancía de valor fundamental y por lo mismo como factor impulsor del desarrollo de las sociedades. Lo que por otra parte viene aparejado con el desarrollo de las tecnologías de la información: todo lo cual ha impactado 
profundamente a la $\mathrm{ByD}$, la que tratando de ponerse en consonancia con tales procesos ha buscado asimilarse a lo más actual de las tendencias informativas y tecnológicas, bajo el estatuto, un tanto acrítico, de "renovarse o morir". Y renovarse en la mayoría de los casos es entendido sólo como un marchar hacia delante, un estar pendiente del futuro. La contracara de semejante tendencia renovadora es que pierde de vista lo ya recorrido con anterioridad, con lo que, paradójicamente, se corre más el riesgo de morir. La renovación sustentada en el fundamentalismo futurista obnubila el pasado con lo que cercena el continnum que da unidad a la temporalidad del pasado con el presente y el futuro. La auténtica renovación ha de forjarse primeramente con la recuperación del pasado. Esto ha tenido grave repercusión e ByD puesto que afecta su organización y orientación. El campo de la ByD, en su actual etapa de desenvolvimiento, vislumbra el futuro hacia el que con incertidumbre se dirige. Pero a cambio, en una relación directamente proporcional, va dejando de mirar atrás, con lo que las huellas dejadas en su largo recorrido comienzan a difuminarse. Lo que, en otras palabras, viene a significar que la historia de la ByD en cualquiera de sus múltiples escorzos, ya no despierta gran interés para ser estudiada por los propios bibliotecólogos y documentalistas. Lo que ocupa los reflectores de mayor interés son temas de carácter más coyuntural, en específico los referidos a cuestiones tecnológicas. El investigador español Emilio Delgado López-Cozar haciendo un seguimiento del estado de la investigación de las distintas áreas y temas bibliotecológicos y documentales a nivel internacional constata la tendencia mencionada.

Las divergencias más significativas son el aumento de los artículos que versan sobre los procesos de automatización (se multiplican por tres) y el descenso de los estudios históricos (caen a la mitad)... Se confirma la pérdida de peso específico de la catalogación y los estudios históricos y la explosión de los temas relacionados con los procesos tecnológicos que desencadenó la automatización de los procesos bibliotecarios y el desarrollo de la recuperación de la información. ${ }^{1}$

Es de señalarse que tal decremento de los estudios históricos, en relación directa con el incremento de estudios sobre tecnología, encuentra razones no sólo en la desbordada oleada tecnológica que impulsa la globalización, sino también en el orden estructural del campo de la ByD; el cual en la actualidad se encuentra sustentado sobre lo que denomino como: orden técnico. Que marca con su impronta a los diversos ámbitos que integran al campo, determinando con ello el predominio tecnológico que orienta de manera futurista su desenvolvimiento.

Es sabido que la técnica es un componente consustancial de la ByD, pero en cuanto tal es un componente más. Sin embargo se va a convertir en un factor predominante con la progresiva incorporación de la tecnología más avanzada, estatuyéndose así bajo el designio de un orden técnico, lo cual redunda en la conformación de una mentalidad técnica entre los miembros del campo que actúa como divisa identificatoria entre ellos, pero además como factor que determina la visión y los procesos cognoscitivos respecto a las prácticas y objetos de conocimiento propios de la ByD. Tal mentalidad técnica va

\footnotetext{
${ }^{1}$ Delgado López-Cozar, E., La investigación en biblioteconomía y documentación, España, TREA, 2002, pp.111-112.
} 
a contramarcha de la recuperación histórica del pasado. Lo que implica que el campo va a estar expuesto a la dinámica impulsora que subyace a las tecnologías de la información en boga: signadas por la vertiginosa obsolescencia, lo que las empuja a un desbocado futurismo, que ha cercenado sus nexos con el pasado. A esto hay que añadir que el discurso que acompaña a las "nuevas tecnologías" genera una seducción que encubre el hecho de que los artefactos tecnológicos en términos simples son sólo un compuesto de partes y funciones. Discurso que redunda en la fascinación que los hace mayormente deseables: consumir a toda costa el último y más potente modelo de artefacto; lo cual propicia también un futurismo angosto, obnubilado de su pasado. De ahí que semejante ansiedad futurista envuelta en el terno tecnológico haya redundado en gran medida en la perdida de interés por los temas históricos en ByD. Todo lo cual ha puesto en evidencia la grieta que se abre en el seno del campo y que exhibe la escisión que vive en el presente entre su rico pasado y el futuro al que pretende dirigirse.

Una ciencia para seguir ampliando sus horizontes cognoscitivos debe recuperar los pasos dejados atrás para que le sirvan de guía de los pasos que dará hacia delante. Si el campo de la ByD ha de dar el paso que lo conduzca hacia la autonomía que lo acabe por instituir como un campo de conocimiento plenamente científico le resulta del todo necesario recuperar su pasado. Lo que, por supuesto, significa retomar la senda del conocimiento histórico: lo que a la par de ampliar el conocimiento del pasado de la propia ByD podrá restablecer su unidad con su desenvolvimiento presente, con lo que se abrirá la puerta del horizonte futuro, en el que queden perfilados sus múltiples posibles, donde un futuro signado por la tecnología sólo sea una posibilidad entre otras, o, sólo un complemento de otras posibilidades futuras del campo.

Lo dicho hasta aquí deja en claro la pertinencia de llevar a cabo una recuperación de la historia en ByD: recuperación que por lo mismo es una invitación para continuar el cultivo de la Historia y más aún para recordarnos que la ByD son también parte de la historia.

La definición canónica de la historia estipula que es el estudio del cambio de los individuos y las sociedades en el tiempo o, en su resumida variante: el cambio de la vida social. Mas a ésta definición hay que añadir la distinción entre el acontecer real y temporal de las sociedades y la ciencia (relato) que estudia ese acontecer. Tal distinción suele pasarse por alto en algunos contextos que designan con la palabra "historia", tanto al acontecimiento como a la ciencia que lo estudia. Lo que ocasiona algunos problemas de orden cognoscitivo. De ahí que en algunas lenguas se hayan acuñado términos alternativos y diferenciados, como por ejemplo en inglés la distinción entre History y Story o en alemán entre Histoire y Geschichte. En español un término diferenciador es historiografia, aunque adolece de limitantes que soslayan su riqueza como ciencia por avocarse a la dimensión escrituraria del relato. Pero en ésta recuperación que se pretende de la dimensión histórica haré la distinción al caracterizar el acontecimiento (res gestae) con la minúscula inicial historia, mientras que la indagación (ciencia) y el relato de las acciones humanas pretéritas (historiam rerum gestarum) se designarán con 
la mayúscula inicial Historia. El subrayar tal distinción no es oficioso, ya que permitirá especificar cómo inciden tanto la historia como la Historia en la ByD. Y con ello poner en evidencia su estrecha interdependencia.

La remota génesis de lo que será con el correr de los siglos la actividad bibliotecológica documental, se ubica en el momento en que la cultura oral entra en ocaso, para dar lugar a la cultura escrita. La cultura oral, en cuanto a sus formas de generación y transmisión de información tiene una extrema complejidad, que ha sido velada porque se ha tratado de comprenderla desde la posición diametralmente opuesta de la cultura escrita. Pero cuando tratamos de comprenderla sin tal mediación nos asombra su amplitud de posibilidades, con lo que nos da también la medida de lo que hemos perdido con el paso a la cultura escrita. La cultura oral no sólo se limitaba a la producción y transmisión de información por el sólo canal oral-auditivo, también entraban en juego la visualidad que captaba la información por medio de imágenes y símbolos. Pero lo más extraordinario era que el cuerpo mismo se convertía en fuente informativa al transmitir mensajes a través del movimiento, fueran bailes o ritos que ritmaban la vida colectiva: nacimiento y muerte. Por lo que bien pude decirse que la corporeidad en conjunto era el soporte de la información y adquiría fijación y continuidad en un amplio espectro de la memoria que aunaba precisamente lo corporal con lo auditivo y visual. Memoria de gran potencia y alcance que satisfacía plenamente las necesidades de las culturas orales.

Con el surgimiento de organismos políticos estables, que a su vez dieron lugar a los primeros reinos y posteriormente a su secuela los imperios, quedaba rebasada la cultura oral. Por lo que surgió la necesidad de registrar de otra forma una información que se incrementaba exponencialmente al compás del crecimiento de los mencionados organismos políticos y sociales. Todo lo cual impulsó la creación de instrumentos técnicos como la escritura y los sistemas de computación cronológica del tiempo, ello permitió ordenar y sistematizar en forma continua el pasado compartido por la comunidad, ahora organizada en una amplia unidad política y territorial. Así, el nacimiento de la escritura conllevó la subordinación a ella de los distintos lenguajes (oral, corporal, visual, musical) que interactuaban y daban forma a la cultura oral. Lo que de manera obvia redundó que la memoria obnubilara su vasta potencia de acumulación de información, para descargarla en el registro escrito; con lo que se gesta un tipo de memoria desconocido hasta ese momento: la memoria escrita. Peculiar forma de memoria que ya no tiene como asiento de gestación, acumulación, preservación y despliegue la mente humana, en la cual sólo quedará una forma limitada de memoria, para cubrir necesidades individuales inmediatas de cada persona. La memoria escrita será en adelante atesorada en archivos y bibliotecas. Instituciones que ya en el mundo antiguo fundado en la cultura escrita tendrán una importancia primordial para el orden social.

Los archivos y bibliotecas encarnaron ya desde la antigüedad el espíritu y la materialidad de la cultura escrita. Por lo mismo tales instituciones son producto del devenir histórico, representan los cambios que en su marcha la historia va propiciando entre las diversas sociedades. Así la historia indetenible en su discurrir temporal de la sociedad dio lugar a la transición de la cultura oral a la cultura escrita, y con esta última a sus instituciones más características y representativas: las cuales ya en sí mismas 
contenían el germen de lo que con el transcurrir de los siglos daría lugar a los múltiples elementos que irían constituyendo al universo bibliotecológico y documental, que con ello dejaba en claro la presencia de la historia en ella, pero también de la proyección de lo bibliotecológico en la Historia. Así la voz de la historia recorre el campo de la ByD.

Con lo que quedaba de esta forma puesto el marco para que se estableciera la inalienable relación dialógica entre la ciencia de la Historia y la ciencia Bibliotecológica. Relación además signada por el movimiento donde: cada una es causante y causada por la otra. De ahí la natural y estrecha relación de la Historia con ByD. Pero esto lleva a plantearnos las preguntas que nos servirán de guía entre los meandros de tal relación, para así dejar claramente de manifiesto la necesidad del cultivo perenne de la Historia: ¿Cómo se establece la relación entre ByD con la Historia? y, ¿Para qué se lleva a cabo la relación entre ambas formas de conocimiento?

\section{III}

Una de las consecuencias de que con un mismo término se designe al acontecimiento histórico y a la indagación (relato) histórico, es que puede derivar en que se tenga la percepción del historiador como un testigo directo y privilegiado del pasado, pero en semejante percepción se soslaya lo obvio: es del todo imposible por el simple hecho de que la materia del historiador, que es el pasado, ya pasó. Por lo que no puede tener con el pasado, con cualquier pasado aunque no sea de su especialidad, un contacto presencial directo. Sólo puede acercarse al pasado, y esa es su condición de posibilidad como historiador, de manera mediada, indirecta y diferida. Al acontecimiento específico del pasado elegido para su estudio el historiador accede por mediación de los vestigios que de tal pasado deja bajo la forma documental, como lo explica el historiador (y teórico de la Historia) francés Paul Veyne:

Este límite es el siguiente: lo que los historiadores denominan acontecimiento no es aprehendido en ningún caso directa y plenamente; se percibe siempre de forma incompleta y lateral, gracias a documentos y testimonios, digamos que a través de tekmeria, de vestigios. ${ }^{2}$

El pasado, como el presente, es producto de un vertiginoso, y casi podríamos decir infinito, entramado de acontecimientos (que pueden ser conglomerados de hechos, acciones, procesos, instituciones, estructuras y personas) pero sólo dejan un número finito, sumamente limitado de documentos y testimonios. Lo que, por otra parte, no significa que todos sean documentos históricos, puesto que antes de ser tocados por la mano del historiador únicamente son los restos del naufragio del pasado.

La desbordada variedad de acontecimientos del pasado se ofrece en una breve fracción de datos que se plasman en una restringida cantidad de documentos (y entiéndase estos de manera amplia). Pero estos no llegan tal cual al historiador, como si este recogiera los restos del naufragio a la vera de una playa desierta. Y a partir de unir

${ }^{2}$ Veyne, Paul, Cómo se escribe la historia. Foucault revoluciona la historia, España, Alianza Universidad, 1971, p. 14. 
tales restos reconstruyera el navío del acontecimiento histórico. La historia encarnada en sus vestigios donde encuentra en gran medida desembocadura es en las bibliotecas, archivos, museos, etc. Es en tales instituciones donde al pasado le es insuflada la reviviscencia, a partir de reunir, organizar, preservar y difundir los documentos en que se ha plasmado. Ahora bien, todo documento se encuentra transido de historicidad; incluso los documentos creados en tiempo presente, y esto por no hablar de los documentos que ya son recibidos directamente del pasado, una vez que son incorporados, por ejemplo, a la biblioteca son preservados ahí, lo que significa que se acunan en la temporalidad de la historicidad. El tiempo los recorre para convertirlos en documentos del pasado, atesorados en una biblioteca para ser ofrecidos al público, entre los cuales obviamente se encuentran los historiadores: son ellos los que hacen de la historicidad del documento un documento histórico. Por lo que no todo documento alcanza el rango de histórico, a menos que sufra la intervención del historiador; más para que tal intervención pueda llevarse a cabo el documento previamente hace un recorrido que queda signado por los procesos que realiza sobre él la biblioteca o, más exactamente hablando, el bibliotecario por vía de la ciencia bibliotecológica y documental.

El conocimiento bibliotecológico, por mediación de la biblioteca, trabaja con la información registrada (universo informativo generado por la cultura escrita) por lo que los documentos recibidos como vestigios del pasado o como producción presente son organizados por medio de procesos técnicos, para con ello ponerlos a disposición del público. Pero visto desde el enfoque histórico esto significa que el documento que ingresa al universo bibliotecario de ser producto de la historia se convierte en potencia en documento de la Historia. Por lo que la insoslayable mediación bibliotecológica esta presente y es determinativa a la hora en que el historiador selecciona un documento para convertirlo en histórico por vía del proceso que el implementa sobre el documento: la interpretación. Por lo que es en esa fase cuando se establece el movimiento de interacción entre Historia y Bibliotecología.

La biblioteca ofrece una amplia gama de documentos, organizados por el conocimiento bibliotecológico, de los cuales el historiador selecciona los que le son pertinentes para el estudio que lleva a cabo del acontecimiento histórico que le ocupa. Por lo que puede decirse que la Bibliotecología es causa de la Historia que desarrolla el historiador. Pero una vez que el historiador comienza a ordenar los documentos seleccionados, los va transfigurando en documentos históricos, proceso que se completa cuando emprende su interpretación. Con lo que el documento ya es parte integral de la Historia. Llegado el historiador a este punto el movimiento se revierte: para ser causante de la conformación del documento bibliotecológico con el añadido histórico.

El documento histórico (producto de la Historia) al pasar ahora, con ese plus, por las manos del profesional bibliotecario es causante de que asuma de forma diferente a tal documento, que ya no es un documento igual a los demás, sólo homologados por el proceso técnico (clasificación, catalogación...) que se ha implementado en ellos. Además y, primordialmente, le brinda el sentido y la conciencia de lo histórico y, por ende, de la construcción de la Historia, más exactamente, de su propia Historia. La propia Bibliotecología en su larga y ancestral historia (desde las primeras bibliotecas en 
el mundo antiguo, pasando por la conformación de la figura del bibliotecario, hasta llegar a la constitución de la ciencia, el conocimiento bibliotecológico) ha producido los documentos que hablan de sí misma: muestran como se ha desenvuelto a través del tiempo; son documentos que dan razón de su inherente historicidad. Así el historiador le señala el camino al bibliotecario para que se acerque a los documentos que hablan de su propio pasado y que a partir de ellos haga su propia Historia bibliotecológica: interpretar sus documentos, para luego elaborar el relato de ese pasado, en sus múltiples vertientes, comprendiendo así su presente. El ya citado historiador Paul Veyne también añade que el conocimiento histórico no sólo se circunscribe al mero tratamiento de los documentos; ellos son el motivo que propicia la elaboración del relato histórico:

La historia es, por esencia, conocimiento a través de documentos. Pero, además, la narración histórica va más allá de todo documento, puesto que ninguno de ellos puede ser el acontecimiento mismo. No se trata de un fotomontaje documental ni presenta el pasado $<<$ en directo, como si estuvierais allí mismo $>>$. Utilizando la útil distinción de G. Genette, la historia de la diégesis y no mímesis"3

Por medio del relato histórico que laboriosamente construye el historiador sobre una base documental (objeto de interpretación: pilar sobre el que se levanta la narración) se da unidad y coherencia al pasado, a la par de tender el puente entre el pasado distante y el presente incierto, esto también es brindado al bibliotecario para que emprenda el relato de su pasado, que le ha hecho ser lo que en la actualidad es. Pero además ese relato restablece la continuidad entre el pasado y los posibles futuros. Lo que significa que un futuro donde se privilegia la orientación técnica no es exclusivo: el horizonte de los múltiples posibles es más amplio.

Como se ha podido apreciar en base a lo expuesto hasta aquí, entre la Historia con ByD existe una sólida y estrecha relación dialógica, puesto que se encuentran unidas a partir de un objeto central de conocimiento para ambas: los documentos; los cuales se estatuyen en el factor que articula el movimiento de interacción entre ambas formas de conocimiento, donde son simultáneamente causantes y causadas una de otra. Lo que nos permite comprender el complejo entramado de relaciones que las une. Todo lo cual da respuesta a la pregunta de cómo son las relaciones entre Historia y Bibliotecología. Pregunta que a su vez nos remite a la consiguiente pregunta del ¿para qué la relación entre la Historia con la ByD?

\section{IV}

Se escribe la Historia para el presente; en otras palabras: buscamos conocer el pasado para comprender nuestro presente. No se trata de conocer el pasado por el pasado mismo. Desde el momento en que la Historia se avoca al conocimiento de la historia convierte a ésta en una vía de acceso para clarificar el horizonte presente; lo cual se da a través de un doble movimiento: explicar el presente a partir de sus antecedentes pasados y comprender el pasado desde el presente. Así en el primer

${ }^{3}$ Ibid., p. 15. 
movimiento el presente se torna legible en base a todos los avatares del pasado que desembocan en la configuración del momento actual. En el segundo movimiento el pasado se torna conocido cuando proyectamos en él todo aquello que conforma nuestro presente. Estos dos movimientos expresan el afán de lo que los seres humanos buscan y encuentran en la Historia: saber de donde venimos para entender lo que somos en el presente. Lo cual puede ser extendido a la ByD, cuando ésta se coloca bajo los designios de la historia. Lo que asimismo significa asumir como una deidad tutelar de la Bibliotecología a la Historia.

La historia tiene un movimiento interior que hace que se generen los antecedentes del pasado que desembocan en el presente. Pero ese movimiento no lo vemos directamente, de hecho cuando nos asomamos al pasado lo apreciamos como lo acabado, lo que ya no es, en suma: como lo muerto. Nuestra mirada sobre el presente no nos permite ver de manera inmediata los hilos con que en la penumbra el pasado teje ese presente, cada presente. El movimiento de la historia comienza a tornarse legible y, por ende, a mostrar que tiene algo vivo, que no es sólo lo muerto, cuando deja testimonio de sí en los documentos. Aunque, es de precisar, que ese asomo de lo vivo del pasado se deja ver cuando los documentos sobre todo son tamizados por la actividad propia de los bibliotecarios: los documentos salen del silencio del anonimato, para mostrar que el pasado no ha acabado aún.

Pero los documentos tratados por los bibliotecarios muestran una ambivalencia: por un lado lo que de vivo hay del pasado con la pervivencia de los documentos; pero también lo que de acabado tiene tal pasado, puesto que son documentos que aunque han sido organizados, aún no dejan escuchar la voz de la historia. Los historiadores son los que al interpretar los documentos hacen que el pasado se convierta en algo vivo, que actúa en el presente. Los documentos, organizados por el bibliotecario, ofrecen una información de acontecimientos ya ocurridos, el historiador desde su visión y perspectiva los interpreta, lo que significa que los hace interactuar al conjugar una narrativa que muestra el movimiento de la historia. Movimiento que clarifica cómo el pasado es el antecedente del presente; mejor aún, es el que da forma al presente.

También esto nos muestra como desde los conocimientos que tenemos del presente, tanto bibliotecológicos (universo de la información) como históricos (concepción del devenir de las sociedades), nos sirven como instrumentos para comprender el pasado. Todo lo cual hace que la Historia sea una forma de conocimiento que permite conocer el presente. Lo que le da la pauta a la ByD para comprender el presente, su presente, en función del pasado, de su propio pasado. Lo que por otra parte redunda en que podamos comprender el sentido del desenvolvimiento de cada sociedad, de las sociedades en conjunto y de la ByD inserta en el devenir de las sociedades (así como en su desenvolvimiento interno), desenvolvimiento que desembocará en el presente.

La Historia al comprender el pasado en aras del presente le brinda a los pueblos o sociedades un origen común que pueden distinguir en el día a día actual. El conocimiento del pasado nos remonta a un origen remoto, primigenio, fundacional que conforme se despliega a lo largo de la historia da cohesión y sentido colectivo a pueblos y sociedades. Sabemos de donde venimos y cómo hemos cambiado a lo largo del tiempo, para comprender quienes somos hoy. Así la Historia al hablarnos del origen y 
cómo este ha gravitado en el desenvolvimiento de los grupos humanos les permite el conocimiento de sí mismos, que es la fragua donde se forja la identidad. Uno de los privilegios, por consiguiente, de la Historia es el de dotar de identidad a pueblos y sociedades. Lo que refuerza el sentimiento de continuidad y los lazos de solidaridad entre los miembros del grupo. El espacio habitado se complementa con el proyecto de convivir juntos para dirigirse al futuro. Este privilegio de la Historia visto desde el interior de la ByD debería redundar en la conformación de su identidad a partir de la recuperación de su pasado, gestado desde ese remoto origen en que se estatuyó la cultura escrita. Ese momento fundacional de la actividad bibliotecaria signó con su impronta el glorioso recorrido de la actividad y el conocimiento bibliotecológico y documental que preserva la información registrada de la humanidad. Todo lo cual debería de contribuir a afirmar los sentimientos de continuidad y solidaridad entre los miembros del campo de la ByD, para así proyectar su futuro. Pero como ya se explicitó líneas atrás, esa identidad de la ByD construida históricamente ha sido difuminada porque ésta pretende encabalgarse en la cresta de la ola tecnológica. Lo que, por otra parte, va aparejado con el gradual olvido de invocar la deidad tutelar de la Historia.

También la marginación de la Historia ha obnubilado la profunda conjunción de fundamentos que se da entre la Historia y la ByD como detentadoras de la memoria colectiva. La Bibliotecología, por vía de los documentos, es receptora de los datos que dan cuenta de los acontecimientos de las diversas épocas. Y en cuanto tal preserva en y para la memoria de las sociedades la información registrada del pasado. Pero es una memoria circunscrita a la información contenida en el breve espacio del documento. Por su parte la Historia al recoger y ordenar los acontecimientos y conocimientos del pasado se convierte en el gran almacén de la memoria colectiva: la que por estar nutrida por la narrativa de la Historia recrea la vitalidad y el movimiento del acontecimiento histórico. Al suministrar la Historia a la Bibliotecología ese sentido de vitalidad y movilidad del pasado los documentos se trasfiguran. La información contenida en los documentos sale de su mutismo para dejar de ser meramente un conjunto de datos estáticos, por lo que estos quedan transidos por el fragor de las pasiones humanas. Detrás de cada dato plasmado en un documento se encuentra la vorágine de afanes, expectativas, sueños, logros y desastres, esto es, grandeza y miseria, de cada sociedad, de cada época histórica: es el sonido de la vasta gama de pasiones que pone de manifiesto la condición humana, que viene a ser el origen del aura humanista de la ByD. Humanismo que encuentra en primera instancia fundamento en su propio objeto central de conocimiento: la información registrada. Es de señalarse que en la Bibliotecología se suele hacer radicar su dimensión humanística en la relación entre bibliotecarios y usuarios. Pero tal concepción humanista es en realidad una proyección o derivación, como se explicó arriba, de la emanación humanística del propio objeto de conocimiento bibliotecológico y documental, la información registrada. Recordemos que lo que media la relación entre el bibliotecario y el usuario es el documento o, más exactamente, la información en él contenida. Por lo que debería ser desde el documento donde se expandiera el aura humanista que propiciara la relación humana entre bibliotecario y usuario. $Y$ no como suele ser en realidad una relación de 
desconocimiento y, por ende, deshumanizada. De ahí la importancia que adquiere también la lectura como vía de acceso a un documento nimbado de historicidad.

Aunque es nuevamente de subrayarlo, la dimensión humanista de la ByD se torna legible siempre que haya una conjunción con la Historia, u otras disciplinas humanísticas. Y es este fundamento humanístico de la ByD lo que ha quedado empañado por la predominancia del orden técnico en el campo. La fascinación tecnológica ha encubierto uno de los atributos sustanciales de la ByD: ser una ciencia humanística que, es de añadir, a su vez se intersecta con las ciencias sociales. Así, al conjugarse la Historia con la ByD exhiben su sustancial fundamento humanístico. En particular a la ByD el humanismo le permite ser una guía para autodefinirse y a la vez ha de ser su guía en el tempestuoso mar del futuro. Con lo que queda en parte contestada la pregunta del para qué se lleva a cabo la relación entre ambas formas de conocimiento. Es de añadirse que tal respuesta tiene un colofón: la proyección de ese humanismo más allá de las fronteras de ambas disciplinas. Quien nos da la pauta para comprender esto es el filósofo mexicano Luis Villoro, quien al dar respuesta al ¿para qué la Historia? implícitamente termina por expresar lo mismo para la ByD:

Este sería, en suma, el último móvil de la historia, su "para que" más profundo; dar un sentido a la vida del hombre al comprenderla en función de una totalidad que la abarca y de la cual forma parte: la comunidad restringida de otros hombres primero, la especie humana después y, tal vez, en su límite, la comunidad posible de los entes racionales y libres del universo. ${ }^{4}$

Como ya se explico, la ByD ha empañado su fundamento humanístico debido a su actual sustentación en un orden técnico, lo que ha redundado en una desorientación respecto a su proyección futura. Por lo que si retoma el camino del humanismo (lo que significa reconstituir sus relaciones con los diversos saberes humanísticos) en primera instancia a partir de la historia, compartirá también lo que las palabras de Luis Villoro entrañan: dar sentido a la vida de los seres humanos, a partir de enmarcarla en una totalidad que la abarca y de la que forma parte insoslayable. Ha ese dar sentido a la vida del hombre la ByD, desde un fundamento humanístico, aporta su propia especificidad, mostrar los grandes afanes de los hombres por dejar testimonio de sí mismos en cada época histórica a través de la información y el conocimiento registrados: es una historia que habla por medio de los documentos de los fulgores y oscuridades de la compleja condición humana.

${ }^{4}$ Villoro, Luis, et., al., Historia ¿Para qué?, México, Siglo XXI, 1981, p. 52 